\title{
Ceremonia de Apertura del AÑo ACADÉMICO 2019*
}

Opening Ceremony of 2019 Academic Year

Manuel Bello Domínguez ${ }^{1}$

Sres. autoridades de la mesa, profesores eméritos, ex rectores, invitados especiales, directivos y docentes, estudiantes, personal administrativo, familiares y público en general:

\section{Homenaje}

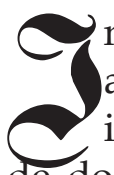
nicio este discurso felicitando a las autoridades de la universidad por la incorporación de un grupo excepcional de docentes a la condición extraordinaria de profesores eméritos. Se trata de un merecido reconocimiento a su trayectoria y aporte personal y colectivo. Pero quiero destacar que es nuestra institución la que más gana al proclamar la continuidad del vínculo académico y moral con cada uno de ellos, más allá de las normas y los plazos formales de finalización de la relación laboral.

Como herediano, he sido testigo cercano y frecuente de la constante e invalorable contribución de todos los colegas homenajeados, al desarrollo institucional y al crecimiento del prestigio de la UPCH, en todas las facetas de la vida universitaria. Han destacado en sus múltiples roles de liderazgo, tanto en espacios o momentos especiales como en la marcha cotidiana de la universidad, inspirando a varias generaciones de jóvenes docentes y estudiantes. Gracias queridos profesores por su compromiso y su protagonismo.

\section{Desafíos Universitarios}

A propósito del ejemplo de protagonismo de los profesores eméritos, me dirijo ahora a los jóvenes que inician su vida universitaria este año, para invitarlos a vivir su experiencia estudiantil también como verdaderos protagonistas. Esta nueva etapa de su vida incluye desafíos muy interesantes, tanto individuales como sociales. Por un lado, están las tareas de construcción de su propia identidad y de su personalidad como adultos, como profesionales exitosos y como ciudadanos responsables. Por otro lado, están los retos compartidos, tales como contribuir al fortalecimiento de nuestra universidad, promover los cambios que necesita nuestro

1 Profesor principal. Facultad de Educación, Universidad Peruana Cayetano Heredia (UPCH). 
país, aportar al desarrollo de la ciencia y la tecnología, y defender el pensamiento académico, racional y crítico, frente a las amenazas crecientes de la irracionalidad y del negacionismo.

A nivel global, el período de formación universitaria que ahora inician coincide con un momento extraordinario para la humanidad, marcado al mismo tiempo por procesos contradictorios como la fascinante revolución de las tecnologías, el cambio climático que amenaza a la supervivencia del ser humano, y el compromiso internacional con los Objetivos de Desarrollo Sostenible, conocidos como Agenda 2030, en los que se expresa una visión universal optimista de la vida de todas las personas sobre el planeta.

Ustedes han terminado el colegio y ahora tienen la oportunidad de estudiar en una universidad que les ofrece educación de buena calidad y la posibilidad de un futuro brillante. Pero no olviden que el Perú es un país muy desigual, en el que muchos jóvenes de su edad no han logrado ni podrán terminar la educación secundaria, obligados a trabajar para sobrevivir, o por tener que asumir una maternidad prematura y no deseada.

El desarrollo personal hacia la adultez es una tarea que deben asumir, que no pueden vivir de manera pasiva o resignada; es una tarea que demanda esfuerzos y aprendizajes, que dependen de la voluntad y el empeño puesto en aprovechar las oportunidades. A eso me refiero con la invocación a ser protagonistas de esta etapa de sus vidas: ser agentes activos y estratégicos del desarrollo personal, con metas, iniciativas y proyectos, y no simples espectadores o receptores de los estímulos que ofrecen las familias, los amigos, o los profesores. Nunca acepten ser actores secundarios en una vida protagonizada por otros.
La tarea del desarrollo personal comprende varias dimensiones, pero la vida universitaria otorga especial importancia a los procesos cognitivos superiores, como el pensamiento abstracto, el lenguaje y el "juicio moral". Estas dimensiones no maduran espontáneamente solo por el paso del tiempo; por el contrario, su desarrollo depende de determinadas experiencias, que las activan y las ejercitan. No todas las personas logran los niveles más altos del funcionamiento cognitivo, que permiten -por ejemplo- seleccionar lo importante en una situación compleja, hacer deducciones o inferencias, anticipar consecuencias, elaborar estrategias para solucionar problemas, criticar y argumentar con fundamento, diferenciar creencias supersticiosas de afirmaciones con base racional o científica, y aprender en forma activa e independiente.

El juicio moral, por otra parte, es la capacidad para distinguir entre el bien y el mal desde una perspectiva social y humanista, en función de valores y principios, y no haciendo prevalecer los intereses individuales o grupales. La actual crisis de corrupción que afecta a nuestro país nos obliga a todos a atender con prioridad el desarrollo del juicio moral, como condición esencial de la ciudadanía y de la convivencia social. Debemos ser intolerantes con la corrupción en cualquiera de sus manifestaciones, grandes o pequeñas; no podemos permitir que algunos individuos sin escrúpulos se beneficien indebidamente, perjudicando a nuestras comunidades.

El desarrollo del pensamiento y del juicio moral, y de otras áreas de la personalidad, depende de la interacción con los demás, de la participación en actividades y en procesos sociales. Se aprende y se crece leyendo mucho, escuchando mucho y, sobre todo, preguntando mucho. Preguntando a los compañeros, a los docentes, a los tutores, a los consejeros y 
a las autoridades. Se crece pidiendo ayuda y aprovechando todos los servicios que ofrece la universidad. Y también se aprende enseñando: los conocimientos se consolidan cuando tenemos la oportunidad de explicar a un compañero algo que él no ha logrado comprender. El aislamiento y la arrogancia egoísta no son una buena opción.

Todos somos integrantes de comunidades, en varios planos y dimensiones. Somos parte de una familia, de un barrio, de una provincia; hemos sido miembros de un colegio, compartimos la pertenencia a un país, a una región, somos integrantes de la especie humana. Ustedes, estudiantes, ahora se han incorporado a esta comunidad llamada Universidad Peruana Cayetano Heredia, y en su interior integran una promoción en alguna de las carreras que ofrece la universidad. Ser protagonista también es prestar atención a la vida que fluye en las comunidades e identificar las oportunidades y retos, para aprender en todos los espacios y crecer como seres humanos plenos, en interacción con los demás.

Pregúntense, por ejemplo, ¿cómo quieren que sea su relación de estudio y convivencia con sus compañeros de promoción, este año y a lo largo de toda la carrera? Lo habitual es que se impongan dos características de la cultura universitaria tradicional: la expectativa del éxito individual, y la competencia por ser el mejor o uno de los primeros de la promoción. Por logeneral, las dinámicas competitivas delos cursos producen un grupo de estudiantes con rendimiento alto, otro con notas intermedias y otro con notas bajas y hasta desaprobatorias. Este modelo educativo tradicional se inspira en la teoría de Darwin sobre la selección en la evolución de las especies: los más fuertes sobreviven, en tanto que los más débiles se van quedando en el camino.
Pero la educación no tiene por qué ser selectiva; existe una alternativa superior a la selección, y más humana, que es el modelo de la educación inclusiva. Este nuevo modelo educativo propone que el éxito individual sea solo una parte de la finalidad de la enseñanza, que aspira y espera el éxito de todos; en la educación inclusiva se pretende que todos aprendan, que nadie se quede atrás. $Y$ la competencia se puede usar, en algunos momentos, como en los juegos y en el deporte, pero se subordina a la cooperación, que es la clave para que todos logren los objetivos. ¿Les parece una utopía? No lo es. Sugieran a sus docentes que las actividades de los cursos se organicen de modo que todos aprendan, que todos logren los objetivos, que todos aprueben, recurriendo para ello a estrategias de enseñanza y aprendizaje basadas en la cooperación y no en la competencia. Si logran algo así en sus cursos ya habrán empezado a cambiar el mundo.

Hablemos ahora de esa comunidad un poco más grande que el grupo de aula y la carrera, que se llama Universidad Peruana Cayetano Heredia, con ocho facultades y muchas carreras y posgrados. Esta universidad, ustedes deben saberlo, no tiene dueños, no pertenece a una empresa nacional o internacional, no depende de alguna organización religiosa. $\mathrm{La}$ "Cayetano" es una asociación sin fines de lucro, laica, integrada por todos sus docentes permanentes y por todos sus estudiantes, comprometida con el desarrollo del país y no con los intereses de algún grupo empresarial, político o religioso.

Ahora ustedes son integrantes de esta asociación, participarán en procesos electorales para elegir a sus representantes y -a partir de segundo año- podrán ser candidatos $\mathrm{y}$ ser elegidos para participar en los consejos de facultades, en el consejo universitario 
o en la asamblea universitaria. Esta universidad, a diferencia de otras, se gobierna democráticamente y les permite a ustedes ser protagonistas también en la gestión, en la vida y la historia de la institución, no solo en el campo de los estudios.

La historia de esta universidad es fascinante $\mathrm{y}$ ustedes tienen que conocerla pronto $\mathrm{y}$ se sentirán orgullosos de ella. Hay libros y artículos publicados sobre la epopeya de la fundación y las ya casi seis décadas de vida institucional. Les hablarán de los fundadores, que forjaron la "Cayetano" para el país y para jóvenes como ustedes, y nunca reclamaron un derecho de propiedad individual para ellos mismos o para sus familiares. Pronto conocerán esa historia. Lo que yo quiero contarles ahora es que, recientemente, nuestra universidad aprobó un plan institucional para cinco años, que se estará ejecutando mientras ustedes realizan sus estudios de pregrado.

Una característica interesante de este Plan Institucional es que toma como marco orientador al documento de la Organización de las Naciones Unidas que establece los Objetivos de Desarrollo Sostenible al año 2030, que ha sido aprobado y firmado por 193 países del mundo, incluido el Perú. Los Objetivos de Desarrollo Sostenible, también conocidos como "Agenda 2030", tienen mucho que ver con los objetivos de la universidad y con lo que se espera de ustedes como estudiantes y como futuros profesionales e investigadores. Al vincularse institucionalmente a la Agenda 2030, la "Cayetano" nos invita a todos a ser protagonistas en la realización de un ambicioso plan de alcance planetario.

El propósito de la "Agenda 2030" es la erradicación de la pobreza, la lucha contra el cambio climático y la reducción de las desigualdades en el mundo entero. Consta de
17 Objetivos de Desarrollo Sostenible y 169 metas asociadas a ellos. Voy a mencionar solo algunos que nos desafían como universidad, como profesionales, como investigadores y especialmente como estudiantes de la UPCH.

Por ejemplo, quienes van a estudiar Nutrición, Veterinaria y Zootecnia, carreras vinculadas a la salud materno infantil, entre otras, tienen como reto el Objetivo de Desarrollo Sostenible $\mathrm{N}^{\circ} 2$ que propone lo siguiente: "Poner fin al hambre, lograr la seguridad alimentaria y la mejora de la nutrición y promover la agricultura sostenible." Por su parte, aquellos que van a estudiar carreras relacionadas con las ciencias de la salud y de la vida, como Medicina, Tecnología Médica, Enfermería, Salud Pública, Administración en salud, Estomatología, Biología o Psicología, deberán ayudar a lograr el Objetivo $\mathrm{N}^{\circ}$ 3, que dice: "Garantizar una vida sana y promover el bienestar para todos en todas las edades". Se pretende, entre otras metas, reducir la tasa de mortalidad materna, poner fin a las muertes evitables de niños menores de 5 años, poner fin a las principales epidemias, fortalecer la prevención, reducir a la mitad las muertes y lesiones causadas por accidentes de tránsito, y garantizar el acceso universal a servicios de salud sexual y reproductiva.

Como mencioné antes, se trata de 17 Objetivos de Desarrollo Sostenible, y varios más tienen relación directa con las áreas de docencia y de la investigación en nuestra universidad. Es el caso del Objetivo 4, que apunta a lograr educación de calidad para todas las personas, y de los Objetivos 14 y 15, que se refieren a la conservación y sostenibilidad de la vida en el mar y en los ecosistemas terrestres, respectivamente. Todos estos desafíos globales, tan importantes para el Perú, enriquecen nuestra visión sobre el rol presente y futuro de nuestra universidad, y sobre el 
importante papel que ustedes podrán jugar en su realización efectiva como protagonistas, ahora como estudiantes y más tarde como profesionales e investigadores.
Estimados estudiantes, docentes, autoridades, profesores eméritos, invitados especiales, personal administrativo, padres de familia $y$ amigos, les deseo a todos un excelente y muy productivo año académico 2019. 